\title{
PROCESSO DE
}

\section{INSTITUCIONALIZAÇÃO \\ DO SEIS SIGMA EM UMA}

EMPRESA AUTOMOBILÍSTICA

THE SIX SIGMA PROGRAM INSTITUTIONALIZATION PROCESS

IN AN AUTOMOBILE COMPANY 


\section{RESUMO}

O trabalho pretende analisar o processo de institucionalização do programa seis sigma em uma empresa automobilística, localizada na região do ABC no Estado de São Paulo. Temas recentes e polêmicos nos estudos organizacionais brasileiros, o movimento neo-institucionalista e os novos modelos de gestão da qualidade serviram de base para esta pesquisa. Por se tratar de um projeto de dissertação, o artigo apresenta os resultados obtidos depois da validação de um instrumento de pesquisa junto a especialistas na implementação da metodologia do seis sigma. Por meio da aplicação de uma triangulação metodológica, composta por questionários e entrevistas, foi possível identificar o estágio de institucionalização do programa e concluir que a consolidação deste ainda não foi atingida. A validação do instrumento de pesquisa utilizado servirá de apoio às futuras pesquisas relacionadas à teoria institucional.

\section{PALAVRAS - CHAVE}

Seis sigma; Teoria institucional; Processos de institucionalização; Qualidade; Indústria automobilística.

\section{ABSTRACT}

The present article intends to analyze the institutionalization process on the six sigma program in the automobile company, located in $\mathrm{ABC}$ region at São Paulo state. Being about dissertation project, the article presents the results gotten in the validation of research instrument through answers by specialists in the six sigma program implementation. By applying questionnaires and interviews it was possible to identify the periods of institutionalization steps and to validate a research instrument to be used in future research.

\section{KEYWORDS}

Six sigma; Institutional theory; Institutionalization process; Quality; Automobile industry. 


\section{INTRODUÇ ̃̃O}

A indústria automobilística é uma das atividades industriais de maior importância para a geração de inovações, de empregos e de renda no mundo. No Brasil (IEDI, 2004; ANFAVEA, 2004), não de outra forma, esse segmento com 87 anos de história é responsável por:

I. trabalho formal: 90.807 postos de empregos diretos;

2. investimentos em novas práticas e tecnologias de trabalho, que fizeram-no obter um aumento de produtividade de I02\% na última década, para uma média de $35 \%$ do setor industrial brasileiro;

3. introdução e difusão da inovação: $: 0,89 \%$ (P\&D/Vendas), enquanto a média nacional é de $0,64 \%$;

4. aumento do valor adicionado em $40,5 \%$, contra uma média nacional de $26 \%$.

Esses números mostram as grandes transformações que essa indústria, já consolidada, está passando nos últimos anos. Uma dessas grandes mudanças ocorreu entre I980 e I990 com o movimento do gerenciamento da qualidade total. Pressionadas pelos avanços gerenciais e tecnológicos japoneses, as empresas americanas adotaram medidas drásticas para recuperarem o tempo perdido e, posteriormente, as difundiram para suas filiais no mundo.

Passado o salto de produtividade e aumento da satisfação dos clientes na década de I990, essas empresas perceberam que a demanda por inovações foi requisitada novamente, devido a pressões sociais, econômicas, políticas ou tecnológicas. A necessidade por um modelo mais sofisticado que o Total Quality Management - TQM (versão americana) ou Total Quality Control - QC (versão japonesa) deu vida a uma nova proposta: o seis sigma, a partir de I980 na Motorola.

Paralelamente a toda essa dinâmica de mudanças e inovações, uma questão organizacional precisa ser destacada: o processo de institucionalização destes modelos, ou seja, as forças ambientais que os fizeram ser assimilados e perpetuados dentro das estruturas organizacionais (ou não) durante décadas.

O presente trabalho será aberto com a apresentação da teoria institucional na administração, suas vertentes, suas críticas e o processo de institucionalização. Na seção 3, o tema será a gestão da qualidade e seus atuais modelos intensamente utilizados pela indústria automobilística - assunto tratado posteriormente. Na seção 5, serão demonstrados a metodologia e os resultados da pesquisa

I. Inovação, segundo Schumpeter (I982) não se restringe a produtos e processos, mas envolve novas formas de gestão, novos mercados e novos insumos de produção. 
que tiveram por objetivo, sob a luz da teoria institucional, construir e testar um instrumento de pesquisa para análise do programa seis sigma numa empresa do setor automobilístico, instalada na região do ABC no Estado de São Paulo. A última seção traz as considerações finais sobre os resultados e coloca a mensuração de fenômenos organizacionais por meio da teoria institucional, uma opção empírica concreta e não apenas teórica.

\section{TEORIA INSTITUCIONAL: EVOLUÇÃO DO CONCEITO}

Apesar de Weber (I997) ter explorado as organizações sob a ótica mecanicista, seus trabalhos dedicaram-se a demonstrar as relações entre os funcionários e os escritórios. Entretanto, foram estudiosos das ciências sociais como Merton, Selznick e Gouldner, entre I940 e I950, que identificaram reações imprevistas dos membros dessas entidades. March e Simon (1975, p. 65) alertaram para o fato de que as estruturas desses trabalhos são bastante semelhantes. Todos os estudos utilizaram como variável independente alguma forma de controle das atividades dos membros da organização. Como sustentaram os autores, no modelo de Merton, o aprendizado disfuncional da organização é temachave, ou seja, seus membros fazem com que reações próprias e determinadas situações se estendam a outras situações semelhantes, trazendo ações desejadas ou não pelas organizações. Esse processo de perpetuação de ações é o fio condutor do que será, posteriormente, explorado nos processos de institucionalização.

As mudanças na personalidade dos indivíduos integrantes dessas organizações provêm de fatores extrínsecos às próprias estruturas organizacionais. Isso aconteceu, inicialmente, em parte por exigências de controle da direção superior sobre o comportamento dos seus membros, assegurando, conseqüentemente, uma confiabilidade.

[...] normas primitivamente elaboradas para presidirem à persecução dos objetivos da organização adquirem um valor positivo próprio, independente daqueles objetivos. Esse fenômeno é chamado de deslocamento de objetivos e ocorre sob duas situações: através de uma atividade provocada por um estímulo condizente ao fato e que, através de sucessivas situações parecidas e repetições do processo de escolha, evoca-se uma gradual transferência de preferência, fazendo com que essa passe a não ser mais o objeto final e sim uma atividade instrumental; ou através de escolha de uma alternativa desejada que produza conseqüências de valor posi- 
tivo, mesmo quando não gera resultados inicialmente previstos (fenômeno chamado de reforço secundário). Nesse último caso, a dinâmica da organização produz conseqüências para as pessoas e unidades, geradas pelas atividades que são motivadas pela própria organização (MARCH; SIMON, I975, p. 66).

Todos os mecanismos acima podem produzir rigidez de comportamento dos participantes, diminuir as relações personalizadas criando corporativismo, e aumentar o grau em que os objetivos são percebidos como comuns a todos os membros do grupo, ou seja, o relato acima dá indícios das primeiras reflexões sobre a ação e participação dos indivíduos na criação de normas que moldarão a conduta organizacional. Por sua vez, esse mesmo grupo criará mecanismos de proteção contra pressões externas, dificultando a mudança. Nesse contexto, os principais agentes de mudança tornam-se os membros da organização e não o contrário, como apontavam os estudos anteriores à Escola de Relações Humanas.

Já no modelo de Selznick (I97I), o destaque fica por conta da delegação de autoridade. O trabalho do autor tenta mostrar a delegação de autoridade como técnica de controle que pode gerar conseqüências imprevistas. A delegação aumenta o grau de treinamento em assuntos especializados, gerando um aumento da departamentalização que, por sua vez, procura reduzir a distância entre os objetivos da organização e sua realização. Esse mecanismo cria uma bifurcação de interesses entre esses departamentos, estimulados pelo treinamento especializado que a delegação produziu. Todo esse processo aumenta os custos de substituição do pessoal que, por sua vez, resulta em aumento acentuado da diferenciação entre os objetivos e as realizações da empresa. Outro interessante aspecto desse processo é que a bifurcação de interesses aumenta o conflito entre subunidades da organização. Por esse motivo, o teor das decisões tomadas pelas organizações fica cada vez mais dependente de considerações estratégicas internas (dos departamentos). Como resultado final, ter-se-á não a redução entre os objetivos e realizações, mas sim o aumento dessas diferenças, gerando ineficiência e mais delegação.

Um aspecto que merece destaque dentro do trabalho de Selznick (I97I) é a preocupação em explicar as relações das organizações com a estrutura exterior (que é uma das abordagens da teoria institucional). Para o cientista, a realidade exterior influencia as práticas organizacionais e, nessa análise, algumas premissas devem ser consideradas:

a) alguns programas, políticas, valores, missão, visão, regras e procedimentos são criados e moldados de acordo com filosofias oficiais dos grupos dominantes, evocados autoconscientemente. As ideologias administrativas são 
- O PROCESSO DE INSTITUCIONALIZAÇÃO DO SEIS SIGMA EM UMA EMPRESA AUTOMOBILÍSTICA • ROBSON QUINELLO

concebidas em planos conscientes e inconscientes pela comunicação e autodefesa (que garantirá a continuidade institucional);

b) a perpetuação de valores dentro do contexto organizacional é criada e protegida pela elite;

c) nasce, dentro de grupos competidores, o conflito dos interesses na busca de influência e dominação. Além disso, esses grupos são impulsionados pela necessidade da sua subsistência e somente uma mudança na distribuição de poder fomentado pelo desejo social (por meio de uma crise) é que pode mudar o cenário.

Segundo March e Simon (1975), Gouldner traz marcas de Selznick e Merton em seus trabalhos e explora as conseqüências que as diretivas administrativas causam na estrutura organizacional como, por exemplo, diminuição da visibilidade das relações de poder, questionamento da legitimidade do papel da supervisão, níveis de tensão interpessoal e desempenho em nível mínimo. Uma ressalva feita pelos autores é no que diz respeito à comprovação desses modelos feitos, sobretudo, por técnicas de observação de organizações isoladas.

\subsection{A TEORIA INSTITUCIONALE O NEO-INSTITUCIONALISMO}

Inicialmente, antes de explorar o tema central dessa seção, vale lembrar alguns conceitos de instituição.

De acordo com Prates (2000, p. 9I), o termo instituição significa: "valores e normas sociais estáveis que impõem restrições a alternativas de ação ou estabelecem scripts e rotinas comportamentais adequadas a contextos específicos de interação social". O centro dessa discussão está na redução de incertezas no âmbito social e na legitimação dos sistemas de valores e normas que compõem as instituições.

Para Selznick (I97I), instituição é definida como um produto de um processo natural de equilíbrios das pressões sociais, às quais elas tentam se adaptar. Alerta ainda que se trata de um fenômeno criado pelo idealismo de um grupo cujos interesses estão interagindo e podem não ser declarados explicitamente (algumas necessidades estão ocultas dentro da sociedade). Estas necessidades são supridas pela instituição ou por suas ações. "Instituição é a transformação de um ordenamento técnico de blocos de construção em um organismo social" (SELZNICK, I97I, p. I20).

Por que as organizações tomam as formas que elas têm? Essa é a questão central do modelo teórico institucional, de acordo com Hall (i998, p. 289).

A teoria institucional ainda é um campo da análise organizacional com dilemas a serem resolvidos, pois, na verdade, ainda precisa "institucionalizar-se", 
ou seja, como o modelo tem sido utilizado para o estudo de uma vasta gama de fenômenos, desde expansões políticas até formulação de políticas nacionais e internacionais em organizações governamentais, precisa-se criar métodos de mensuração padronizados, metodologia de pesquisa e variáveis que permitam uma investigação mais aprofundada do fenômeno (TOLBERT; ZUCKER, I998, p. I96).

Desses dilemas, surgiram dois grandes movimentos atuantes:

- a chamada "velha" escola institucional (FLECK, 2004; CRUBELLATE et al., 2004; ROMANO, 2003; POWELL; DIMAGGIO, I99I) fundamentada nos trabalhos de Selznick e colaboradores que investigaram o lado "obscuro" da interação informal nas organizações;

- a denominada "nova" escola institucional ou neo-institucionalista a partir da década de I970, principalmente com a publicação de trabalhos de Meyer e Rowan e Zucker em I977, Berger e Luckman em I967 e Powell e DiMaggio em I99I, que desenvolveram e clarearam os princípios institucionais no contexto das organizações formais.

Powell e DiMaggio (I99I) argumentam que ambos os movimentos enfatizam a relação entre organizações e seus ambientes inconsistentes, até então, no campo das organizações formais. As escolas reforçam os papéis culturais na formação da realidade organizacional. Ainda no campo neo-institucional, Powell e DiMaggio (I991, p. 67-73) identificam três diferentes mecanismos nas mudanças no isomorfismo institucional: a) isomorfismo coercitivo - ligado, sobretudo, às questões de influências políticas e problemas de legitimidade, resultado de pressões formais ou informais; b) isomorfismo mimético - vinculado principalmente aos padrões, como resposta, às incertezas ambientais (muitas vezes representando uma força poderosa para o processo de imitação); e c) pressões normativas - originária, basicamente, da profissionalização que os autores interpretaram como um esforço coletivo de membros de uma ocupação em definir métodos e condições dos seus trabalhos, controlando e estabelecendo bases cognitivas e legitimadas para suas autonomias ocupacionais.

Portanto, as diferenças de definições do foco analítico, do ambiente, da visão de conflito e mudança e da força da ação individual entre as duas escolas são consideráveis.

\subsection{PROCESSO DE INSTITUCIONALIZAÇÃO}

Institucionalização, para Berger e Luckmann (2002), é o processo central no desenvolvimento e perpetuação de grupos sociais duradouros e ações torna- 
- O PROCESSO DE INSTITUCIONALIZAÇÃO DO SEIS SIGMA EM UMA EMPRESA AUTOMOBILÍSTICA • ROBSON QUINELLO

das habituais e aceitas. É uma abordagem da influência de atores individuais e não organizacionais. De acordo com Selznick (I97I, p. I4):

Institucionalização é um processo. É algo que acontece a uma organização com o passar do tempo, refletindo sua história particular, o pessoal que nela trabalhou, os grupos que engloba com os diversos interesses que criaram, e a maneira como se adaptou ao seu ambiente [...] o grau de institucionalização depende da proteção que existe para a interação pessoal com o grupo [...] quanto mais precisa for à finalidade de uma organização e quanto mais especializadas e técnicas as suas operações, menores chances haverá de forças sociais afetarem seu desenvolvimento.

A expansão do processo de institucionalização no nível organizacional iniciou-se com os trabalhos de Zucker no final da década de i970. A autora identificou algumas interferências no modelo inicial de Berger e Luckmann e acrescentou novas propriedades como: autoridade hierárquica, responsabilidades específicas, período de vida potencialmente ilimitado, entre outros, que alterariam o processo institucional nas organizações em diferentes níveis. Inicialmente, Zucker (I99I) demonstrou níveis de institucionalização como processos e nas condições de variáveis. Numa abordagem etnometodológica ${ }^{2}$, o processo de institucionalização ocorreria em três etapas: transmissão de cultura (socialmente construída), manutenção da cultura e resistência às mudanças.

Posterior a esse primeiro esboço do processo de institucionalização, Tolbert e Zucker (I998, p. 204-2I0) voltariam a elaborá-lo, definindo as seguintes etapas:

- habitualização ou estágio pré-institucional - nesse estágio, a organização busca a criação de novos arranjos estruturais em respostas a incertezas ou problemas organizacionais específicos. Soluções testadas com resultados satisfatórios por outras organizações podem estimular a imitação, como processo de difusão, pelos decisores. Inicialmente, essa nova estrutura se desenvolverá de forma heterogênea e com baixa teorização, ou seja, a princípio, as empresas tentarão se moldar às novas condições ambientais. Tem, freqüentemente, curta duração;

- objetificação ou estágio semi-institucional - a busca por um estágio mais consolidado e permanente ocorre nessa fase, que acompanha o processo de di-

2. Etnometodologistas, segundo Zucker (apud POWELL; DIMAGGIO, I99I, p. I06), estudam as culturas emergentes sob dois aspectos: criação de novas culturas e persistência em sua continuidade. 
fusão da nova estrutura, em resposta aos novos desafios. Aqui há a necessidade de consenso social entre os decisores da organização a respeito do valor dessa dada estrutura. Esse consenso poderá surgir por meios externos e explícitos, tais como noticiários, cotação acionária e observação direta que permitirão uma análise mais realista da utilização dessa nova estrutura, criando significado entre os adotantes. Monitoramento dos resultados obtidos por outras organizações pode ser outro mecanismo de interpretação da escolha. Desse modo, quanto mais organizações adotarem, positivamente, certas estruturas, menor será o risco da escolha. Exemplo desse processo é o que foi utilizado pela qualidade total, em que consultores desempenham o papel de defensor das práticas a serem implementadas. Os champions (defensores), de acordo com Tolbert e Zucker (I998), desempenham duas principais tarefas de teorização: a definição clara dos problemas genéricos a serem corrigidos e a justificação de um novo arranjo estrutural formal, por meio da exposição de solução para o problema com bases lógicas e testadas. Esses mecanismos trarão legitimidade cognitiva e normativa, além de facilitar a difusão (que no estágio anterior era apenas imitativo) com bases mais normativas. A taxa de sobrevivência dessas estruturas nesse estágio, apesar de ser mais duradoura, não é definitiva. Como define Abrahamson (apud TOLBERT; ZUCKER, I998, p. 209): “[...] de fato, o destino, geralmente, as investe de qualidade de moda ou mania";

- sedimentação ou total institucionalização - nessa última etapa é trazido o conceito de sedimentação. Aqui, há a continuidade histórica da estrutura adotada, além da sua sobrevivência no longo prazo. Conflitos de interesse e fracos resultados podem pôr em risco a manutenção dessa estrutura, incentivando os decisores a buscarem novos arranjos (se os custos forem relativamente baixos). Sendo assim, a total institucionalização dependerá de: baixa resistência dos grupos de oposição, promoção e apoios contínuos pelos defensores e correlação positiva com os resultados desejados.

A Figura I ilustra as principais etapas do processo de institucionalização de programas, mudanças ou inovações dentro das organizações.

Numa análise ao trabalho de Tolbert e Zucker sobre a teoria institucional, Machado-da-Silva e Gonçalves (I998) argumentam que os estudos conduzidos pelas autoras tratam as instituições como dadas pelo ambiente e que o processo de institucionalização tem caráter qualitativo. Esses trabalhos não se baseiam em relato de pesquisa, mas sim em considerações teóricas de múltiplos estudos. Hasselbladh e Kallinikos (2000) exploram algumas limitações no neo-institucionalismo para as organizações formais. Os autores alertam que existe uma exploração superficial do movimento neo-institucional nos estudos das relações 
entre ambientes racionalizados e organizações formais. A escola não oferecia explicações aprofundadas de como práticas e crenças racionalizadas implicavam em adoção de procedimentos e regras organizacionais.

\section{FIGURA I}

\section{O PROCESSO DE INSTITUCIONALIZACAO}

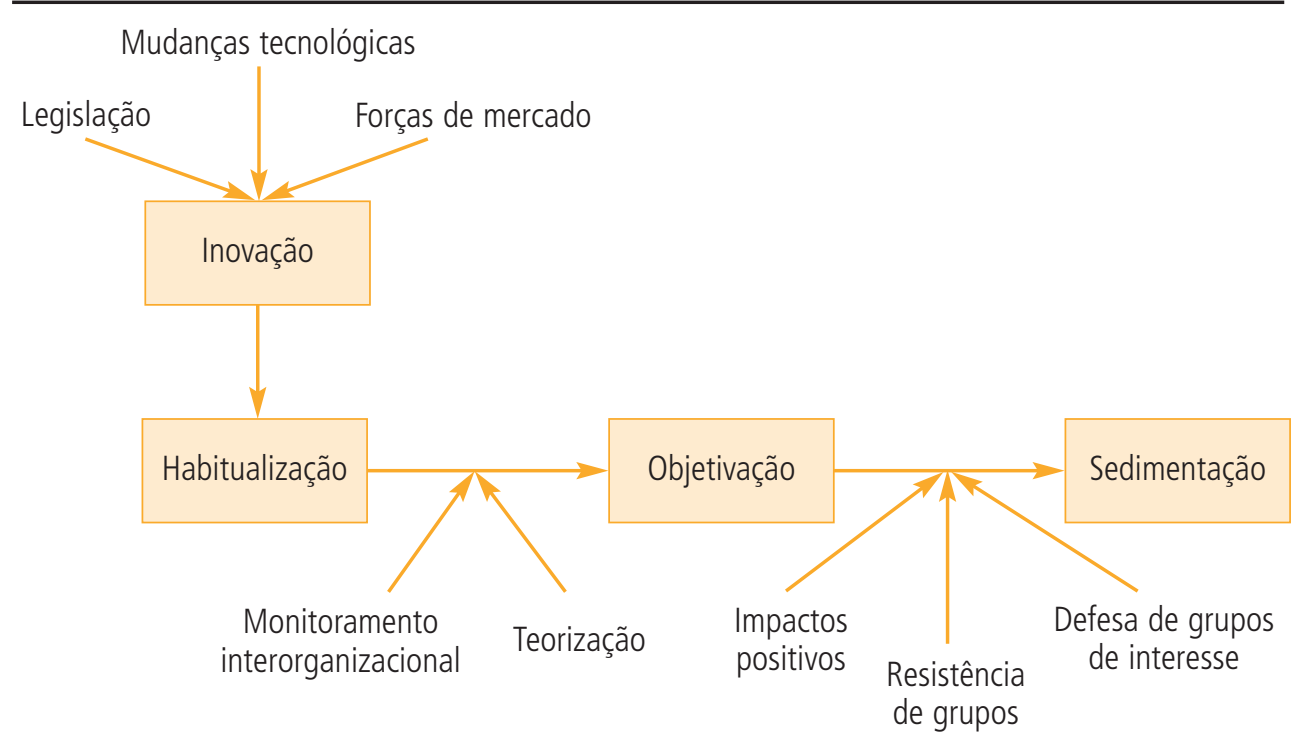

Fonte: Tolbert e Zucker (I998, p. 207).

\section{B QUALIDADE TOTAL}

A busca pela qualidade de produtos e serviços não é um fenômeno novo. Desde os egípcios e os gregos antigos, o homem busca padrões (por exemplo, as pirâmides, a arte e a arquitetura). No século XVIII, o controle daquilo que era considerado bom ou não no processo de fabricação familiar era confinado a um indivíduo ou a um pequeno grupo. Entretanto, a qualidade como um fenômeno digno de estudo só aconteceu no início do século XX com o controle da qualidade (ainda que precariamente). Somente durante a Revolução Industrial e por intermédio do conceito de produção de massa é que surgiu a figura dos responsáveis pela qualidade (inspetores da qualidade). Entre os anos de I920 e I930, Shewhart introduziu os conceitos de estatística para os processos de produção. Já na década de I940, com o início da Segunda Grande Guerra, a necessidade de escala na produção de armas forçou a utilização de controle estatístico da qualidade (MITRA, I998).

Acabada a guerra, o Japão, país completamente destruído, foi visitado por Deming que levou novas idéias aos líderes japoneses sobre qualidade. Subse- 
qüentemente, Juran, em I954, divulgou para o mesmo país experiências da importância estratégica do controle estatístico da qualidade para os negócios das empresas. As décadas de I960 e I970 foram marcadas pela entrada da indústria japonesa automobilística (completamente fortalecida pelos programas de qualidade) nos Estados Unidos, a partir de I980. Essas práticas e ferramentas para o gerenciamento da qualidade receberam muitos nomes, entre eles, TQM - Total Quality Management, TQC - Total Quality Control ou QM - Quality Management. Baseados em princípios e padrões, eles foram responsáveis pelo significativo aumento da produtividade e qualidade dos veículos no mundo.

No Brasil, as primeiras empresas que entraram em contato com a gestão da qualidade foram as do setor nuclear, a partir de i970. Essa expansão tomou maior impulso com a abertura do mercado nacional e com a globalização mundial, a partir de I990, quando surgiu o programa brasileiro de qualidade e produtividade e as câmaras setoriais (ALGARTE; QUINTANILHA, 2000).

\section{1 SEIS SIGMA}

Paralelamente aos movimentos da qualidade, surgiu, a partir de I980 na empresa americana Motorola, um grupo denominado TCS - Total Customer Satisfaction, com o intuito de introduzir nos modelos até então conhecidos (TQM) a voz do cliente, ou seja, atender expectativas de qualidade sob o ponto de vista dos clientes externos e a mensuração financeira dos ganhos obtidos, isto é, quanto de retorno para os acionistas cada ação poderia trazer. O processo consistia no desenvolvimento de projetos (com duração de io meses em média), focados nos problemas de qualidade e satisfação dos clientes, chamados de programa seis sigma. Os times eram compostos de io a I2 membros e liderados por um especialista na metodologia seis sigma denominado black belt (as expressões foram traduzidas para o inglês e têm origens nos guerreiros orientais - os samurais). A Figura 2 mostra uma proposta de estrutura formada pelos membros de uma organização e seus respectivos tempos de dedicação ao programa. Observa-se que os black belts trabalhavam em tempo integral nos projetos; enquanto o restante da estrutura, em tempo parcial dando apoio aos projetos.

Para que os resultados desejados sejam atingidos, são necessárias algumas etapas fundamentais: seleção e projetos (direcionados às metas da empresa), times de trabalho comprometidos, análises estatísticas dos dados coletados, ações consistentes com as causas-raiz encontradas, comparação dos resultados alcançados com os problemas originais e institucionalização (os times devem demonstrar consolidação dos resultados e encorajar a difusão do sucesso alcançado por toda a empresa) (MITRA, I998). 
- O PROCESSO DE INSTITUCIONALIZAÇÃO DO SEIS SIGMA EM UMA EMPRESA AUTOMOBILÍSTICA • ROBSON QUINELLO

\section{FIGURA 2}

ESTRUTURA DO SEIS SIGMA

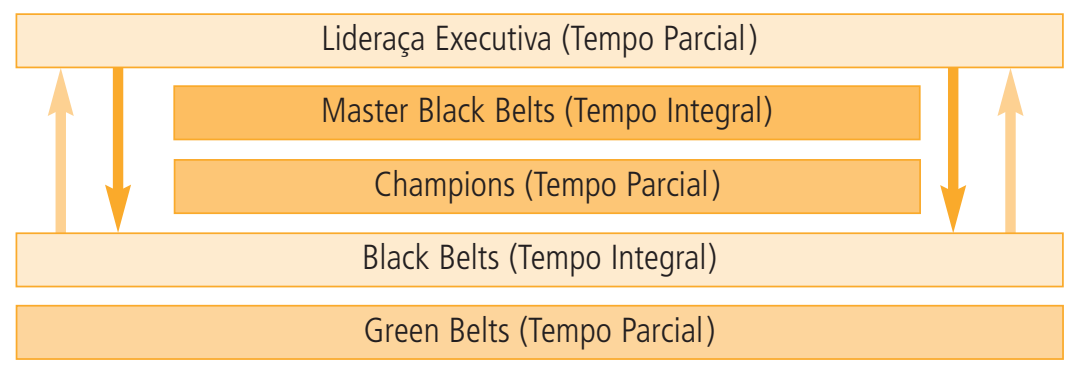

Fonte: Elaborada pelos autores.

Para Smith e Blakeslee (2002), o seis sigma é uma técnica de melhoramento da qualidade altamente baseada em estatística difundida inicialmente nas áreas de manufatura. As empresas também podem utilizá-la na formulação e desenvolvimento das estratégias empresariais e nas mudanças organizacionais. Os autores afirmam que os principais desafios na implementação do programa são criar condições culturais para mudança, forte comprometimento da liderança, mecanismos de incentivo, projetos seis sigma totalmente orientados aos principais problemas da organização, assim como buscar dados tangíveis e quantificáveis. Os projetos seis sigma são desenvolvidos por duas principais metodologias: DMAIC 3 (processos) ou DFSS 4 (novos projetos).

Na Figura 3, temos duas metodologias utilizadas pelo programa: DMAIC e DFSS. A decisão por uma ou outra será dos especialistas em face dos problemas a serem solucionados.

De acordo com Reveres e Black (2003), o seis sigma foi o substituto escolhido das práticas de TQM, uma vez que encontrou as organizações preparadas para as mudanças e desafios necessários no novo mercado mundial. A diferença estaria na reestruturação metodológica que aproveitaria diversas ferramentas estatísticas e métodos de resolução de problemas consagrados em outros modelos para a execução de projetos liderados pelos especialistas - black belts em etapas predeterminadas.

3. O método DMAIC significa as cinco etapas de cada projeto seis sigma (define, measure, analyze, improve e control). É utilizado para processos já existentes e que necessitam de melhorias (STUDT, 2002).

4. O método DFSS (design for six sigma) é utilizado para o desenvolvimento de novos produtos e serviços (TENNANT, 2002). 


\section{FIGURA 3}

\section{AS METODOLOGIAS DMAIC E DFSS}

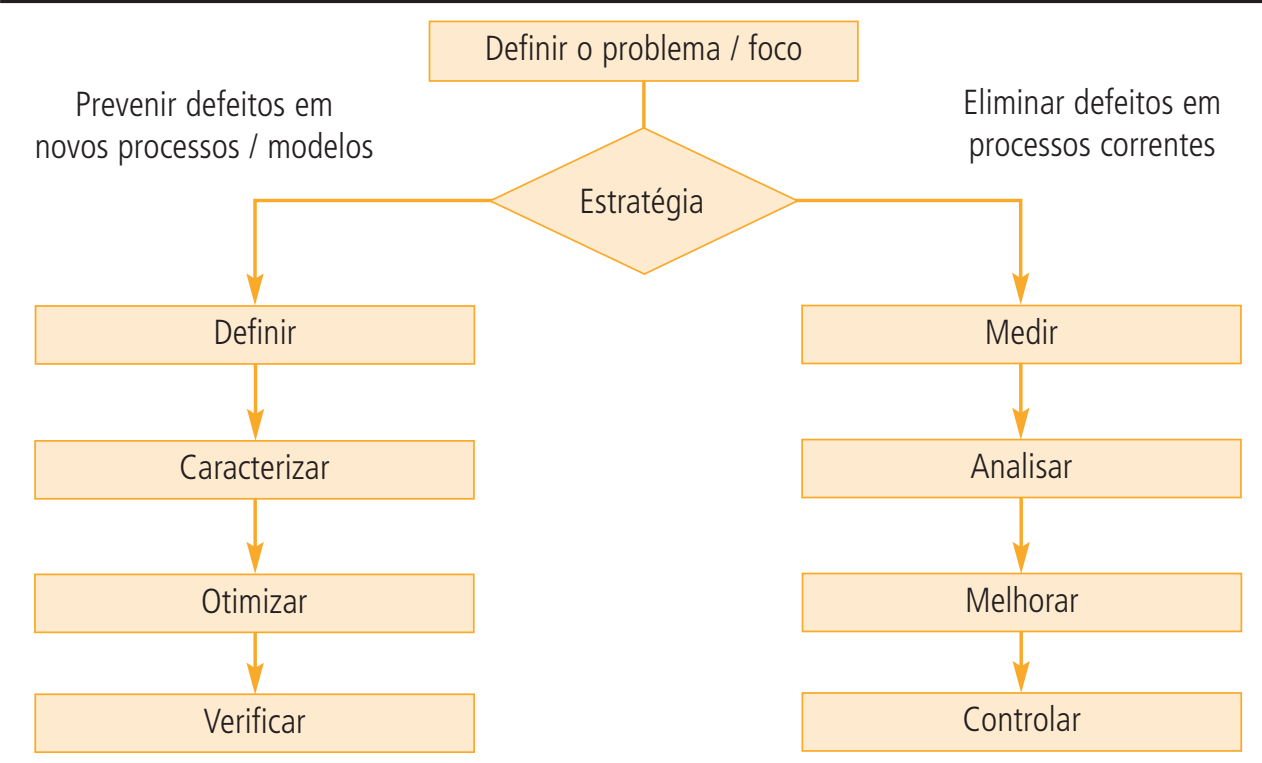

Fonte: Elaborada pelos autores.

Em termos estatísticos, sigma é a i 8 a letra do alfabeto grego e é uma medida de variação. Quando aplicada aos processos, ela é uma medida de quantidade de defeitos ou falhas que podem ocorrer em um milhão de oportunidades; isso significa que, quanto maior o nível sigma, menor a quantidade de defeitos.

QUADRO I

NIVEL SIGMA X DEFEITOS POR MILHÄO

DE OPORTUNIDADES - DPMO

\begin{tabular}{cc}
\hline NÍVEL SIGMA & DEFEITOS POR MILHÃO DE OPORTUNIDADES \\
\hline 2 & 208.537 \\
\hline 3 & 66.807 \\
\hline 4 & 6.210 \\
\hline 5 & 233 \\
\hline 6 & 3,4 \\
\hline
\end{tabular}

Fonte: Elaborado a partir de Tennant (2002).

Nota-se que, à medida que o nível sigma aumenta, diminui-se a quantidade de defeitos ou falhas de um processo. O seis sigma equivale a dizer que um pro- 
- O PROCESSO DE INSTITUCIONALIZAÇÃO DO SEIS SIGMA EM UMA EMPRESA AUTOMOBILÍSTICA • ROBSON QUINELLO

cesso é, praticamente, livre de defeitos ou falhas, isto é, a cada I milhão de produtos ou serviços produzidos por uma organização, apenas 3,4 são defeituosos ou fora das especificações. Numa representação estatística (curva normal), também é possível notar o rigor exigido dos produtos ou serviços seis sigma.

Para Studt (2002) os resultados das empresas que utilizam o seis sigma são expressivos. A Motorola de Schaumburg - Illinois, em mais de I5 anos de implementação, teve um aumento de produtividade de I2\% ao ano, gerando um ganho aproximado de ir bilhões de dólares sobre os custos de manufatura. A General Electric de Fairfield - Connecticut gastou mais de 600 milhões de dólares nos projetos seis sigma em 2002, prevendo retorno de mais de 3 bilhões de dólares nos últimos três anos. Já a Dow Chemical de Midland - Michigan afirma ter economizado mais de 750 milhões de dólares desde 1999 devido às práticas do seis sigma.

No Brasil, em I997, de acordo com Werkema (2002), a Brasmotor foi a empresa nacional pioneira que alcançou ganhos de 20 milhões de dólares, dois anos após a implantação. A Ford Motor Brasil seguiu outras filiais e a própria matriz, em I999, dando os primeiros passos da metodologia, atingiu a marca de I bilhão de dólares em 2002.

Para Caulcutt (200I), uma das dificuldades encontradas para o desenvolvimento do programa nas organizações está na mudança de cultura. Para ele, o gerenciamento deve ocorrer por meio de fatos e não apenas por experiência ou intuição da gerência. Isso é demonstrado pelo cronograma dos projetos que estabelecem revisões dos dados e fases de desenvolvimento. Outro fato importante é que "nas companhias seis sigma a pessoa que detém o poder de decisão não é necessariamente a mais influente"(CAULCUTT, 200I, p. 304). Outro determinante do sucesso do programa é a lembrança de experiências passadas com outras iniciativas de qualidade, como o TQM, quando uma boa implantação faz toda a diferença. O problema de suporte da gerência na GE foi solucionado, pois nesse nível hierárquico há bônus anuais (40\%) ligados diretamente aos resultados dos projetos.

Mergulhão (2003) ressalta que os resultados encontrados num estudo realizado entre duas empresas manufatureiras (AeroSpace e LatAlum) indicaram que as organizações pareciam estar implementando os elementos do seis sigma de forma incompleta e que a maturidade do programa não estava relacionada ao tempo de implantação da iniciativa. Desse modo, o processo de implantação do seis sigma parece estar associada à construção consistente de alguns elementos. Numa das empresas, o programa não estava consolidado e os ganhos financeiros não haviam sido obtidos. O autor, no trabalho, explora alguns elementos críticos como: comprometimento da alta liderança, cultura organizacional, treinamento, estratégia organizacional, foco no cliente e projetos de melhoria. Algumas recomendações, a partir da análise, foram feitas: 
a) elaboração de métodos e critérios para seleção de projetos;

b) análise da estrutura organizacional e de qualificação do pessoal mais adequado ao seis sigma;

c) análise do processo de seleção de ferramentas para os projetos seis sigma;

d) análise do uso do DFSS em empresas brasileiras;

e) discussão do deslocamento de I,5 sigma da média considerada pela metodologia seis sigma, ou seja, se os padrões assumidos pelas empresas que vêm adotando-a teriam capacidade para atingi-los.

Os exemplos acima demonstram que mais do que um programa de qualidade nas empresas, o seis sigma passa (assim com o TQC e o TQM) pela questão da mudança organizacional.

\section{INDÚSTRIA AUTOMOBILÍSTICA}

A indústria automotiva é uma das atividades industriais de maior importância para a geração de emprego, renda e produtos. A reconstrução industrial japonesa, que teve grande impulso na década de I950, criou relevantes modificações nos sistemas de produção industrial em geral, e mais especificamente no setor automotivo - este mais difundido e conhecido como Sistema Toyota de Produção. Basicamente, esse modelo tinha como pressuposto a produção de massa flexível de artigos diferenciados, inserindo operações fundamentadas em novos conceitos de desempenho, qualidade e produtividade, revolucionando o sistema fordista de divisão do trabalho, em que o trabalhador polivalente e autônomo (HIRATA apud LIMA et al., I994) tem papel fundamental.

O modelo de organização, chamado também de ohnoismo devido ao executivo da Toyota, rompeu com o modelo tradicional por apresentar quatro grandes características: a) trabalho em equipe ou em células; b) autonomia aos grupos de trabalho; c) redução dos níveis hierárquicos; e d) reaproximação funcional dentro das empresas.

Com os resultados apresentados pela indústria japonesa e sua posterior entrada no mercado americano na década de I980, a indústria americana reagiu e imitou o processo (da qual foi criadora), estendendo as práticas às suas filias européias, asiáticas e latino-americanas. Para esse modelo ser bem-sucedido, as empresas européias e americanas adotaram novas posturas com relação aos seus fornecedores e compradores, isto é, envolvendo todos os agentes integrantes da cadeia de valores da indústria, iniciando um complexo processo de implementação de sistemas de interdependência e transferência de inovações de natureza tecnológica e organizacional, objetivando uma auto-sustentação desse processo mediante riscos compartilhados, ou seja, de auto-sustentação no longo prazo. Esse novo 
modelo se opunha ao modelo fordista com fornecedores independentes e concorrentes entre si. A base desse novo padrão de relacionamento está na aplicação de técnicas gerenciais, tais como kanban (cartões que identificam quanto será produzido e quando ocorrerá o reabastecimento), just-in-time (visa atender a demanda instantaneamente, com qualidade e sem desperdício) e kaizen (uma série de procedimentos que objetivam a melhoria contínua do processo) (CASTRO, I993).

No Brasil, de acordo com Lima et al. (2000), a reestruturação automotiva chegou na década de I990, quando incentivos ao segmento foram intensificados com o regime automotivo brasileiro, em I996. Este programa que integrava uma estratégia de política governamental, articulou diferentes estágios e instrumentos de política econômica visando obter maior competitividade das empresas já estabelecidas, como também estimular a concorrência definindo regras e estímulos a empreendimentos de origem externa. Esta política já inseria em seu eixo principal o foco no longo prazo, de abertura para o setor expandir as exportações, com concessões gradativas às importações. Em I997, por exemplo, o governo decidiu direcionar os investimentos do setor para regiões menos desenvolvidas (Norte, Nordeste e Centro-Oeste) com o objetivo de acelerar ao mesmo tempo o crescimento e a desconcentração da produção setorial.

O Gráfico I expõe como as mudanças organizacionais, tecnológicas, políticas, econômicas e sociais alteraram a produtividade da indústria automotiva brasileira, em especial nos segmentos montadoras e autopeças, inaugurando um novo padrão tecnológico e concorrencial nas empresas estabelecidas, influenciadas ainda mais pela inserção de veículos importados e de novos concorrentes, tendo em vista a alteração de barreiras protecionistas aos tradicionais fabricantes e montadoras.

GRÁFICO I

RELAÇAO DE PRODUÇAO E EMPREGO NA INDÚSTRIA AUTOMOBILÍSTICA BRASILEIRA

Emprego X Produção (1957-2003)

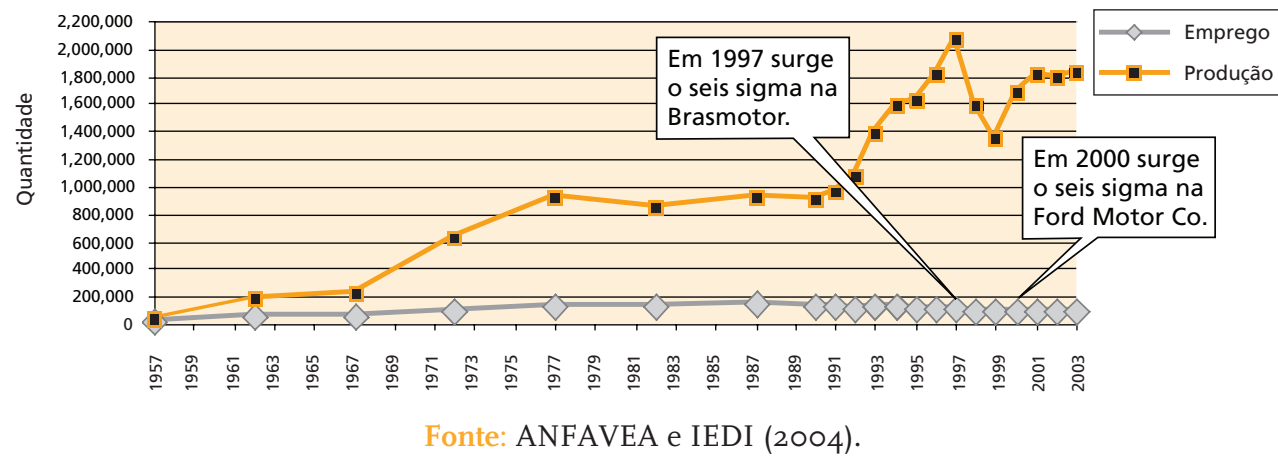


Tal modificação do padrão concorrencial pode ser sintetizada no Gráfico I, pela relação entre a força de trabalho empregada e o comportamento da produção, o que em termos relativos abrange a consolidação de novos modelos de gestão, principalmente aqueles originados da TQM, e da modificação do nível de competitividade dessa indústria, principalmente depois de I990.

\section{METOdOLOGIA DA PESQUISA}

A pesquisa empreendida é de cunho exploratório e, de acordo com Yin (200I), do tipo estudo de caso. Exploratório pois se trata de proposta da construção de um instrumento de pesquisa para mensuração da institucionalidade de programas de qualidade, a partir da análise de um ambiente organizacional bem delineado. Os pressupostos a serem analisados são:

I. Por meio da construção de um instrumento de pesquisa para a mensuração do processo de institucionalização de um programa da qualidade, qual é o grau de institucionalidade do programa seis sigma em uma empresa automobilística localizada no grande $\mathrm{ABC}$, no Estado de São Paulo. Tolbert e Zucker (I99I) sugeriram a triangulação metodológica para estudos ligados ao grau de institucionalização de fenômenos organizacionais.

2. O programa seis sigma, sob a ótica institucional, estaria institucionalizado e consolidado?

O trabalho apresentado fez uso de métodos qualitativos e quantitativos, conforme Figura 4. No método quantitativo, o instrumento utilizado foi o questionário estruturado utilizando escala Likert ${ }^{5}$, aplicado nos especialistas black belts. No método qualitativo, foram utilizados dois instrumentos: entrevistas com questões semi-estruturadas respondidas individualmente pelos champions e entrevista de grupo de foco com questões semi-estruturadas para os black belts. A combinação dos instrumentos subsidiou a análise dos dados e posteriores conclusões.

5. A escala de Likert (ordinal) é a variação mais freqüentemente usada da escala de classificação somatória. As escalas somatórias consistem de afirmações que expressam atitudes favoráveis e desfavoráveis em relação ao objeto de interesse (COOPER; SCHINDLER, 2003). 
- O PROCESSO DE INSTITUCIONALIZAÇÃO DO SEIS SIGMA EM UMA EMPRESA AUTOMOBILÍSTICA • ROBSON QUINELLO

\section{FIGURA 4}

\section{TRIANGULACAO METODOLOGICA ${ }^{6}$}

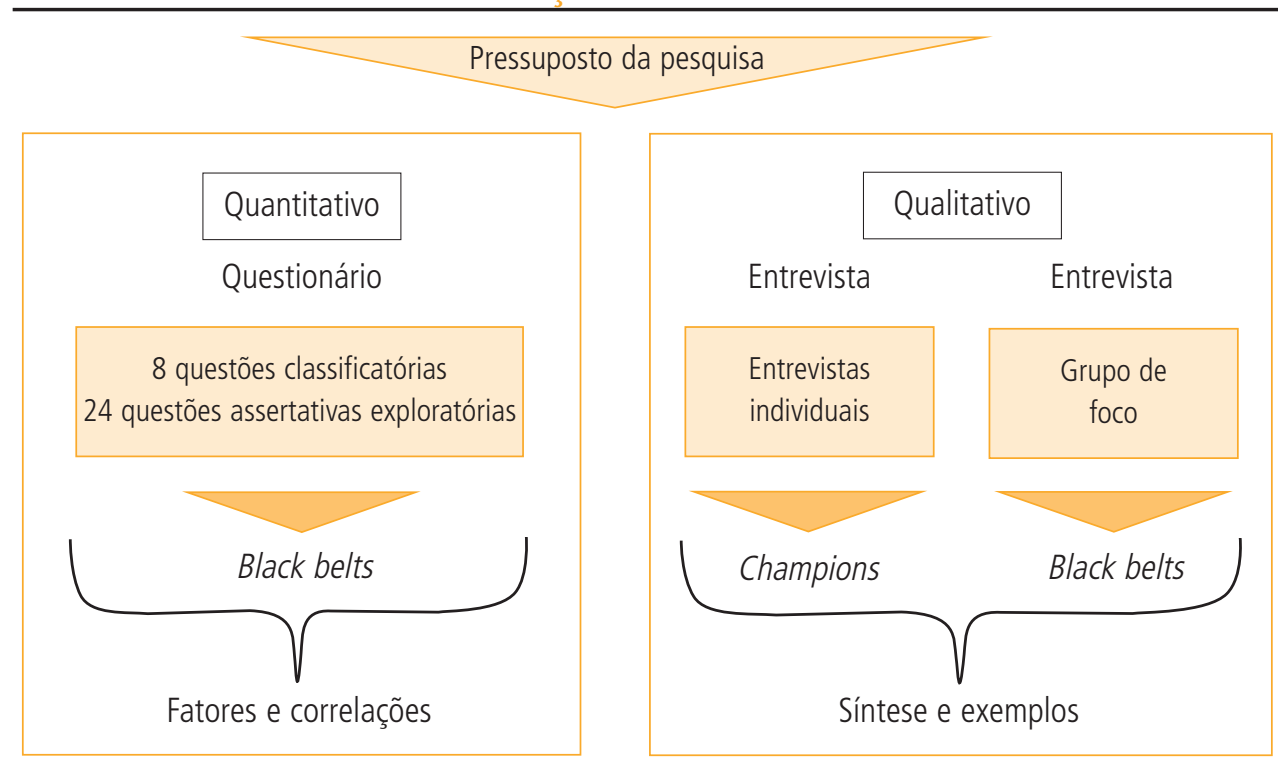

Respostas

Fonte: Elaborada pelos autores.

Tolbert e Zucker (I99I, p. 2II) sugerem: "Qualquer que seja a metodologia usada para coletar dados, no entanto, qualquer afirmação plausível a respeito do grau de institucionalização, provavelmente, residirá numa estratégia envolvendo triangulação de fontes e métodos". Elas indicam a utilização de análise de conteúdo de materiais escritos, de pesquisa tipo survey, de questionários sobre atributos relacionados ao grau de institucionalização e de pesquisa histórica. Acrescentam ainda (p. 2I2,): "O estudo do processo de institucionalização poderá trazer luz ao desenvolvimento e propagação de diversos casos reais de estruturas que tenham sido objetos de teorizações recentes, como os programas de qualidade". Para responder os pressupostos, será adotado o plano conforme Figura 5.

6. Triangulação metodológica, segundo Fleury et al. (I997), é a combinação de técnicas múltiplas (qualitativa e quantitativa) com o objetivo de enriquecer a metodologia de pesquisa pela verificação cruzada dos instrumentos de pesquisa. De acordo com Easterby-Smith et al. (I999), o termo surgiu da navegação em que é tomado no mínimo três pontos de referências para se verificar a localização de um objeto. 


\section{FIGURA 5}

\section{FLUXOGRAMA DA PESQUISA}

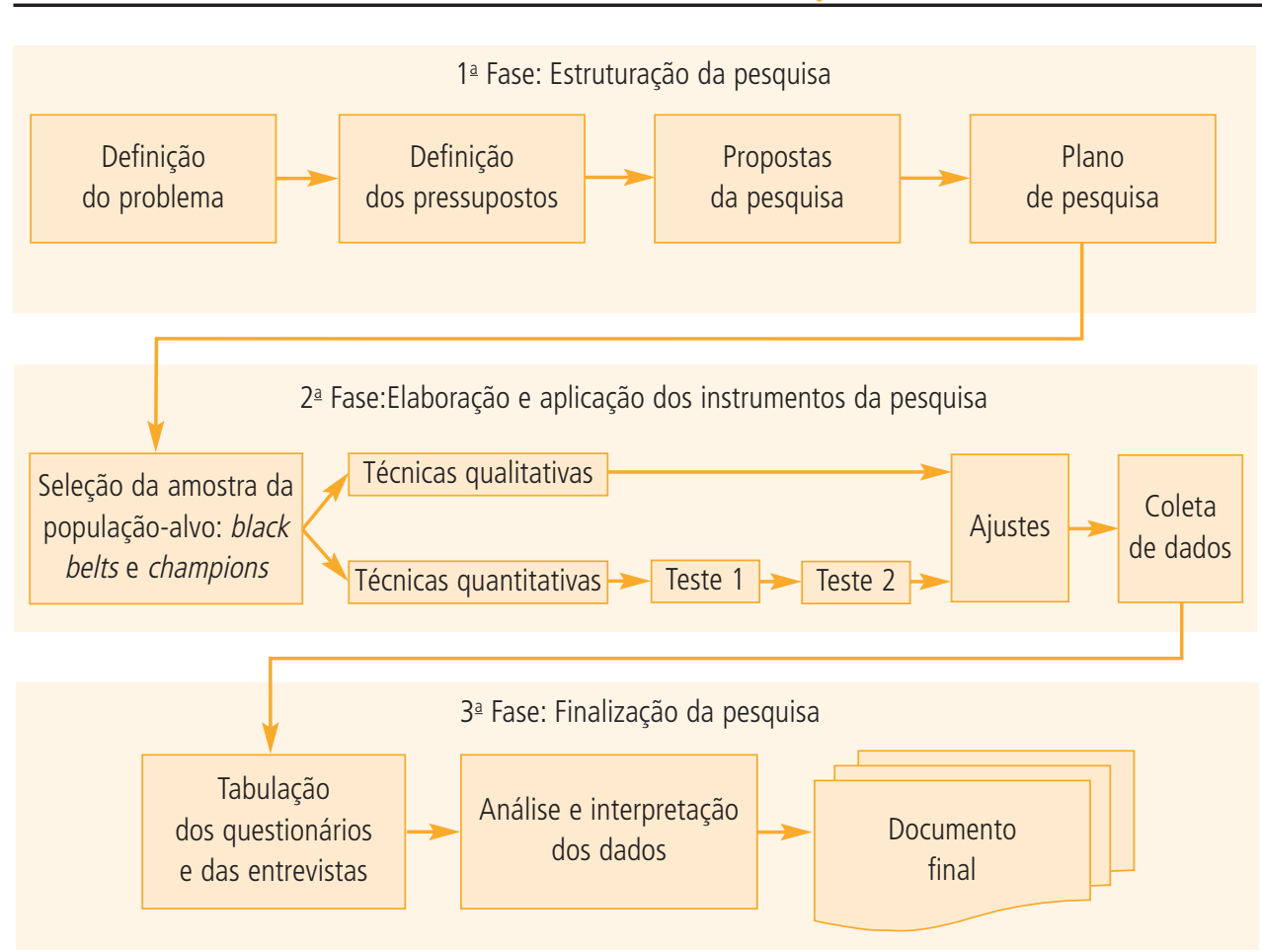

Fonte: Elaborado pelos autores.

O fluxograma da Figura 5 ilustra os passos dessa pesquisa e a aplicação dos instrumentos de pesquisa, que serão abordados nas próximas seções.

\subsection{ELABORAÇÃO DE QUESTIONÁRIO DE PESQUISA}

Para Cooper e Schindler (2003), são necessárias de 20 a 25 questões apropriadamente redigidas sobre um objeto de atitude para uma escala de Likert confiável. As vantagens do questionário utilizando a escala Likert, de acordo com Selltiz (I975), são: I. permite a introdução de qualquer item, empiricamente avaliado e coerente com o estudo, no instrumento de pesquisa; 2 é uma construção simples; 3. é menos custosa. Porém, a desvantagem, ainda segundo o autor, é que a escala Likert analisa favorabilidade de um indivíduo com relação a um determinado objeto, mas não apresenta base para dizer o quanto esse indivíduo é mais favorável que o outro e não mede a quantidade de mudanças depois de certa experiência: "Às vezes o resultado total de um indivíduo tem pouco 
sentido, pois muitos padrões de respostas aos vários itens apresentam o mesmo resultado" (SELLTIZ, I975, p. 267).

A escala adotada varia de i a 5 , sendo o I "concordo plenamente"; o 2 "concordo"; o 3 "indiferente"; o 4 "discordo" e o 5 "discordo plenamente".

Para minimizar as desvantagens acima descritas foi realizado, numa primeira etapa, um teste de validação no mês de setembro de 2004 com cinco black belts e o questionário mostrou-se adequado para a proposta do estudo quanto ao conteúdo, clareza, facilidade, objetividade e tempo (QUINELLO; NUNES, 2004). Após a coleta dos cinco questionários, puderam ser constatadas sugestões e críticas para melhoria do instrumento composto por oito perguntas classificatórias e 24 assertivas exploratórias.

Para cada fase do processo, foram formuladas questões com base na fundamentação teórica e nos constructos-chave do processo de institucionalização proposto por Tolbert e Zucker (I998). Nas questões I a 7, pretende-se analisar as seguintes variáveis: inovação, estrutura, monitoramento interorganizacional, papéis, metas, eficiência e agentes para mudanças. Nas questões 8 a I4, as variáveis verificadas são: política, difusão da estrutura, valor, confiança, aspirações individuais, comunicação e suporte. Nas questões I5 a 24, são observadas as variáveis: conflitos e resistências, sustentação da eficiência, apoio contínuo, difusão, valorização, satisfação, recompensa, consolidação e resultados. Os questionários foram distribuídos entre janeiro e março de 2005 para uma população-alvo de 85 black belts, obtendo-se respostas de 30 especialistas. Como o tamanho da amostra não permitiria conclusões robustas, complementamos a pesquisa com seis entrevistas individuais aplicadas nos champions (executivos e ex-executivos) e um grupo de foco com cinco black belts, criando assim uma triangulação metodológica. As questões elaboradas para ambas as entrevistas analisaram as mesmas variáveis do questionário aplicado.

\subsection{ANÁlISE DOS DADOS}

Após a aplicação dos três instrumentos de pesquisa, constataram-se os pontos mais relevantes que puderam reforçar os resultados gerais do processo de institucionalização do seis sigma na empresa analisada. Os próximos quadros mesclam as respostas das três técnicas utilizadas para cada etapa. Na primeira coluna, teremos os resultados (medianas) dos questionários aplicados nos 30 black belts; na segunda, os trechos mais significativos das entrevistas com os seis champions; e na terceira, os destaques das entrevistas com o grupo de foco.

O estágio de habitualização, também denominado pré-institucional (Quadro I), foi superado pela implantação de um novo modelo, de treinamentos, de processo de comunicação e do apoio do executivo principal. 


\section{QUADRO I}

\begin{tabular}{|c|c|c|c|}
\hline \multirow[b]{3}{*}{$\begin{array}{l}\text { Variáveis- } \\
\text { chave }\end{array}$} & \multicolumn{3}{|c|}{$\begin{array}{l}\text { RESULTADO DA TRIANGULAÇÃO } \\
\text { METODOLÓGICA - HABITUALIZAÇÃO }\end{array}$} \\
\hline & \multicolumn{3}{|c|}{ RESULTADOS OBTIDOS PELOS INSTRUMENTOS DE PESQUISA } \\
\hline & $\begin{array}{l}\text { Questionário } \\
\text { - Valor da } \\
\text { mediana }\end{array}$ & $\begin{array}{l}\text { Entrevistas } \\
\text { individuais com champions }\end{array}$ & $\begin{array}{c}\text { Entrevista } \\
\text { de grupo de foco com os BBs }\end{array}$ \\
\hline Inovação & 2,0 & $\begin{array}{l}\text { Seis sigma considerado inovador e } \\
\text { adotado na hora certa. Imagem do } \\
\text { CEO fortemente ligado ao programa. } \\
\text { Gerência sentiu pressão e indiferen- } \\
\text { ça da alta liderança. }\end{array}$ & $\begin{array}{l}\text { Programa considerado inovador e } \\
\text { adotado no momento certo. }\end{array}$ \\
\hline Estrutura & 3,0 & $\begin{array}{l}\text { Houve algumas mudanças estruturais } \\
\text { na unidade. }\end{array}$ & $\begin{array}{l}\text { Poucas mudanças e adaptações na } \\
\text { unidade. }\end{array}$ \\
\hline Monitoramento & 3,0 & $\begin{array}{l}\text { Houve monitoramento interorganiza- } \\
\text { cional sem modificações ou adapta- } \\
\text { ções (modelo GE). }\end{array}$ & $\begin{array}{l}\text { Não fazem monitoramento intra ou } \\
\text { interorganizacional. }\end{array}$ \\
\hline Papéis & 3,0 & Papéis foram definidos superficialmente. & $\begin{array}{l}\text { Papéis insuficientemente definidos e } \\
\text { não claros. }\end{array}$ \\
\hline Metas & 2,0 & $\begin{array}{l}\text { Objetivos na alta liderança baseados } \\
\text { na metodologia. }\end{array}$ & $\begin{array}{l}\text { Tomadas de decisão pouco alinhadas } \\
\text { na metodologia. }\end{array}$ \\
\hline Eficiência & 2,0 & $\begin{array}{l}0 \text { programa trouxe resultados con- } \\
\text { cretos para a unidade. }\end{array}$ & $\begin{array}{l}0 \text { programa trouxe resultados para } \\
\text { algumas áreas da unidade. }\end{array}$ \\
\hline $\begin{array}{l}\text { Agentes de } \\
\text { mudança }\end{array}$ & 2,0 & $\begin{array}{l}\text { Diferentes condutas entre os respon- } \\
\text { sáveis pela mudança. Os champions } \\
\text { e gerentes reclamam de pressões e } \\
\text { outras prioridades além do seis sigma. }\end{array}$ & Empenho de apenas alguns agentes. \\
\hline
\end{tabular}

Fonte: Elaborado pelos autores.

No estágio seguinte, de objetificação ou semi-institucionalização (Quadro 2), foram detectadas algumas variáveis que impossibilitam o desenvolvimento em busca de consolidação. Esses principais obstáculos estão presentes, principalmente, na falta de preparação e adequação da organização sob os aspectos técnicos e humanos na manutenção do programa.

Sem um arranjo adequado, o seis sigma sofreu com a resistência de grupos, a falta de apoio verdadeiro (não apenas nos discursos) e a inexistência de atividades ligadas ao programa na rotina dos funcionários, criando barreiras para a total institucionalização, conforme Quadro 3. 
- O PROCESSO DE INSTITUCIONALIZAÇÃO DO SEIS SIGMA EM UMA EMPRESA AUTOMOBILÍSTICA • ROBSON QUINELLO

\begin{tabular}{|c|c|c|c|}
\hline \multicolumn{4}{|c|}{ QUADRO 2} \\
\hline \multicolumn{4}{|c|}{$\begin{array}{l}\text { RESULTADO DA TRIANGULAÇÃO } \\
\text { METODOLÓGICA - OBJETIFICAÇÃO }\end{array}$} \\
\hline \multicolumn{4}{|c|}{ RESULTADOS OBTIDOS PELOS INSTRUMENTOS DE PESQUISA } \\
\hline $\begin{array}{l}\text { Variáveis- } \\
\text { chave }\end{array}$ & $\begin{array}{l}\text { Questionário } \\
\text { - Valor da } \\
\text { mediana }\end{array}$ & $\begin{array}{l}\text { Entrevistas } \\
\text { individuais com champions }\end{array}$ & $\begin{array}{l}\text { Entrevista } \\
\text { de grupo de foco com os BBs }\end{array}$ \\
\hline Política & 2,0 & $\begin{array}{l}\text { Existiu preparação de políticas espe- } \\
\text { cíficas para o programa na alta lide- } \\
\text { rança. }\end{array}$ & $\begin{array}{l}\text { Falta de preparação política para a } \\
\text { condução do programa nas camadas } \\
\text { inferiores. }\end{array}$ \\
\hline $\begin{array}{l}\text { Difusão da } \\
\text { estrutura }\end{array}$ & 4,0 & Difusão inicial alta. & $\begin{array}{l}\text { Difusão inicial alta e de manutenção } \\
\text { baixa. }\end{array}$ \\
\hline Valor & 3,0 & $\begin{array}{l}\text { Alguns líderes valorizam o seis sig- } \\
\text { ma. }\end{array}$ & $\begin{array}{l}\text { Poucos funcionários valorizam o seis } \\
\text { sigma. }\end{array}$ \\
\hline Confiança & 2,0 & $\begin{array}{l}\text { Alguns líderes confiam nos projetos } \\
\text { e programa. }\end{array}$ & $\begin{array}{l}\text { Os BBs acreditam moderadamente } \\
\text { nos resultados dos projetos. }\end{array}$ \\
\hline Aspirações & 4,0 & Aspirações individuais pontuais. & $\begin{array}{l}\text { O programa não está em sintonia com } \\
\text { as aspirações de muitos BBs. }\end{array}$ \\
\hline Comunicação & 4,0 & $\begin{array}{l}\text { Comunicação inicial alta e de manu- } \\
\text { tenção baixa. }\end{array}$ & $\begin{array}{l}\text { Pouca comunicação efetiva nas fases } \\
\text { posteriores à introdução do seis sig- } \\
\text { ma. }\end{array}$ \\
\hline Suporte & $\begin{array}{l}\text { Entre } 2,0 \text { e } \\
\qquad 3,0\end{array}$ & Suporte moderado da diretoria. & $\begin{array}{l}\text { Suporte baixo da média gerência e } \\
\text { champions. }\end{array}$ \\
\hline
\end{tabular}

Fonte: Elaborado pelos autores.

QUADRO 3

\begin{tabular}{|c|c|c|c|c|}
\hline \multicolumn{5}{|c|}{$\begin{array}{l}\text { RESULTADO DA TRIA } \\
\text { METODOLÓGICA - SED }\end{array}$} \\
\hline \multirow[b]{2}{*}{$\begin{array}{l}\text { Variáveis- } \\
\text { chave }\end{array}$} & \multicolumn{3}{|c|}{ RESULTADOS OBTIDOS PELOS INSTRUMENTOS DE PESQUISA } & \multirow{2}{*}{$\begin{array}{l}\text { Conclusão } \\
\text { para a variável } \\
\text { analisada } \\
\text { A- alta, } \\
\text { M- moderada } \\
\text { e B - baixa }\end{array}$} \\
\hline & $\begin{array}{c}\text { Questionário } \\
\text { - Valor da } \\
\text { mediana }\end{array}$ & $\begin{array}{l}\text { Entrevistas individuais } \\
\text { com champions }\end{array}$ & $\begin{array}{l}\text { Entrevista de grupo } \\
\text { de foco com os BBs }\end{array}$ & \\
\hline $\begin{array}{l}\text { Conflitos e } \\
\text { resistências }\end{array}$ & 3,5 & $\begin{array}{l}\text { Conflitos e resistências não re- } \\
\text { solvidos, porém naturais. }\end{array}$ & $\begin{array}{l}\text { Conflitos e resistência não } \\
\text { resolvidos. }\end{array}$ & B \\
\hline Sustentação & 2,0 & $\begin{array}{l}\text { Baixa sustentação dos resulta- } \\
\text { dos. }\end{array}$ & $\begin{array}{l}\text { Moderada sustentação dos re- } \\
\text { sultados. }\end{array}$ & M \\
\hline Apoio contínuo & 2,5 & $\begin{array}{l}\text { Há apoio em algumas cama- } \\
\text { das hierárquicas. }\end{array}$ & Apoio contínuo deficiente. & B \\
\hline
\end{tabular}




\section{QUADRO 3 (CONTINUAÇÃO)}

RESULTADO DA TRIANGULAÇÃO

METODOLÓGICA - SEDIMENTAÇÃO

\begin{tabular}{|c|c|c|c|c|}
\hline \multirow[b]{2}{*}{$\begin{array}{l}\text { Variáveis- } \\
\text { chave }\end{array}$} & \multicolumn{3}{|c|}{ RESULTADOS OBTIDOS PELOS INSTRUMENTOS DE PESQUISA } & \multirow{2}{*}{$\begin{array}{c}\text { Conclusão } \\
\text { para a variável } \\
\text { analisada } \\
\text { A- alta, } \\
\text { M- moderada } \\
\text { e B - baixa }\end{array}$} \\
\hline & $\begin{array}{l}\text { Questionário } \\
\text { - Valor da } \\
\text { mediana }\end{array}$ & $\begin{array}{l}\text { Entrevistas individuais } \\
\text { com champions }\end{array}$ & $\begin{array}{l}\text { Entrevista de grupo } \\
\text { de foco com os BBs }\end{array}$ & \\
\hline Difusão & 3,0 & $\begin{array}{l}\text { A gerência percebe dificulda- } \\
\text { de no chão-de-fábrica na utili- } \\
\text { zação do seis sigma. }\end{array}$ & $\begin{array}{l}\text { Os funcionários não utilizam } \\
\text { freqüentemente o seis sigma } \\
\text { nas áreas de manufatura. Nas } \\
\text { áreas de não-manufatura o uso } \\
\text { é maior. }\end{array}$ & M \\
\hline Valorização & 2,0 & $\begin{array}{l}\text { A alta liderança valoriza o pro- } \\
\text { grama (pelo menos nos discur- } \\
\text { sos). }\end{array}$ & $\begin{array}{l}0 \text { seis sigma é um programa } \\
\text { valorizado. }\end{array}$ & A \\
\hline Satisfação & 3,0 & $\begin{array}{l}0 \text { programa trouxe mudança } \\
\text { de paradigma e novas formas } \\
\text { de alocação de recursos. }\end{array}$ & $\begin{array}{l}0 \text { programa não trouxe satis- } \\
\text { fação e gera estresse em algu- } \\
\text { mas áreas. }\end{array}$ & B \\
\hline Recompensa & 4,0 & $\begin{array}{l}\text { Ocorreram falhas no planeja- } \\
\text { mento dos mecanismos de re- } \\
\text { compensa e incentivo. }\end{array}$ & $\begin{array}{l}\text { Raros foram os BBs que as- } \\
\text { cenderam na carreira após o } \\
\text { programa. Houve crescimento } \\
\text { pessoal. }\end{array}$ & B \\
\hline Consolidação & 2,0 & $\begin{array}{l}\text { Os gerentes acreditam na teo- } \\
\text { ria e não na prática. }\end{array}$ & $\begin{array}{l}\text { Os BBs, apesar das barreiras, } \\
\text { acreditam na perpetuação do } \\
\text { seis sigma. }\end{array}$ & M \\
\hline Resultados & $\begin{array}{l}\text { Entre } 2,0 \\
\text { e } 2,5\end{array}$ & $\begin{array}{l}\text { Poucos foram os resultados fac- } \\
\text { tíveis pelo seis sigma. }\end{array}$ & Os resultados foram razoáveis. & M \\
\hline
\end{tabular}

Fonte: Elaborado pelos autores.

O resultado das análises demonstra que o programa seis sigma, passados quatro anos da implantação, está numa etapa de semi-institucionalização, pois as variáveis da penúltima fase de institucionalização apresentam barreiras e sinais de fraqueza; sobretudo na passagem para a terceira etapa, os pontos fracos foram mais acentuados (o programa foi perdendo "fôlego" ao longo dos anos). Contudo, a fase pré-institucional foi superada pela força inicial aplicada nos treinamentos da população, nos mecanismos de difusão (comunicação, por exemplo) e nos rituais e cerimônias (apresentações e discursos da liderança).

Um resumo dos quadros anteriores é apresentado no Quadro 4, mostrando, de maneira geral, como se processou a busca (ou não) pela legitimação: 
- O PROCESSO DE INSTITUCIONALIZAÇÃO DO SEIS SIGMA EM UMA EMPRESA AUTOMOBILÍSTICA • ROBSON QUINELLO

QUADRO 4

RAIO X DO PROCESSO DE INSTITUCIONALIZAÇÂO DO SEIS SIGMA

\begin{tabular}{c|c|c|c}
\hline \multirow{2}{*}{$\begin{array}{c}\text { Fases do processo de } \\
\text { institucionalização }\end{array}$} & $\begin{array}{c}\text { Questionário \% } \\
\text { Medianas desfavoráveis } \\
+ \text { indiferentes }\end{array}$ & $\begin{array}{c}\text { Entrevistas individuais } \\
\text { com champions }\end{array}$ & Entrevistas com BBs \\
\hline Habitualização & 39 & Moderada-Alta & Moderada \\
Objetificação & 47 & Moderada-Baixa & Moderada \\
Sedimentação & 39 & Baixa & Baixa \\
\hline
\end{tabular}

Fonte: Elaborado pelos autores.

Na fase de total-institucionalização, a prática do programa seis sigma deveria ser habitual, aceita, valorizada e não mais questionada pelos agentes, criando, nessa população, valor simbólico (o que não ocorreu). Como ressaltam Berger e Luckmann (2002, p. I40):

O universo simbólico também ordena a história. Localiza todos os acontecimentos coletivos numa unidade coerente, que inclui o passado, o presente e o futuro. Com relação ao passado, estabelece uma "memória" que é compartilhada por todos os indivíduos socializados na coletividade. Em relação ao futuro, estabelece um quadro de referência comum para a projeção das ações individuais. Assim, o universo simbólico liga os homens com seus predecessores e seus sucessores numa totalidade dotada de sentido.

Para o seis sigma obter valor simbólico, ele precisará passar pelas três etapas do processo de institucionalização de forma consistente. Passando pelas etapas, o esforço para manter a imagem do programa é menor, mas em contrapartida o esforço para introduzir uma nova tecnologia será muito maior, criando aqui um novo paradoxo: a força gerada para a busca da legitimação de um programa seria diretamente proporcional à força aplicada para sua deslegitimação como num fenômeno ação-reação.

\section{CONSIDERAÇÕES FINAIS}

Os instrumentos construídos para mensuração mostraram-se adequados para a análise da institucionalização do programa seis sigma. Recomenda-se 
a utilização desta pesquisa tanto para estudos acadêmicos como para os gestores dos programas seis sigma ou outros programas de qualidade, sempre respeitando a contextualização do caso. As limitações do trabalho se deveram principalmente à baixa resposta dos questionários, à dificuldade de interpretação dos fenômenos simbólicos e às poucas pesquisas nacionais sobre o assunto proposto.

No âmbito acadêmico, novos testes e estudos se fazem necessários com o mesmo instrumento de pesquisa e sob as mesmas condições, criando comparações entre empresas de outros segmentos, colaborando com os estudos empíricos de Tolbert e Zucker (I998), que apontam a necessidade de novos testes e instrumentos de medição para a análise do processo de institucionalização. Para reforçar os resultados do questionário, sugere-se sempre uma triangulação metodológica, isto é, a utilização de outras técnicas (entrevistas em profundidade, grupos de foco e outras) para conclusões mais enriquecidas a respeito do programa analisado.

No âmbito dos gestores em geral, fica demonstrada a possibilidade não só de mensuração das fases institucionais do seis sigma, bem como os principais fatores inibidores e incentivadores para a consolidação do programa. Essa análise torna-se essencial para a implementação de uma nova ferramenta de gestão para a qualidade, reconhecidamente custosa monetária e humanamente falando. A velocidade que o cenário concorrencial vem exigindo dos tomadores de decisão no mundo corporativo faz com que as empresas adotem posturas estratégicas mais agressivas e busquem novas concepções e modelos de gestão. O seis sigma vem sendo utilizado por algumas empresas nacionais e estrangeiras no Brasil e, quando implementado de forma adequada, pode ser uma opção. O que foi encontrado na pesquisa foi um programa semi-institucionalizado, com vários desafios a serem superados. No Gráfico 2, feito a partir das medianas dos dados coletados (que variam numa escala de I a 5, sendo o I mais favorável à institucionalização e o 5 menos favorável), foi possível configurar o padrão de institucionalidade do programa:

O Gráfico 2 mostra a conformação do processo de institucionalização do seis sigma nas três fases (habitualização, objetificação e sedimentação). Quanto mais distantes estiverem os pontos do centro do gráfico, menos favoráveis as variáveis estarão para completarem a fase de institucionalização total do programa. Apesar de o programa ter superado a fase inicial do processo, não se pode afirmar que ele esteja completamente legitimado, estando num estágio intermediário chamado pelos institucionalistas de semi-institucional. Há indícios de que o programa tem mais caráter político do que técnico e seus resultados estão muito mais ligados à imagem que a adoção de novas práticas traz ao mundo corporativo do que às metas apregoadas pela literatura (como a satisfação dos clien- 
- O PROCESSO DE INSTITUCIONALIZAÇÃO DO SEIS SIGMA EM UMA EMPRESA AUTOMOBILÍSTICA • ROBSON QUINELLO

tes e o retorno aos acionistas). O esforço para reerguer o programa (se for o caso) será igual ou superior ao inicial e demandará dos gestores estratégias de resgate bem sólidas. O trabalho procurou fornecer sustentação àquelas empresas que já estão adotando o programa, detectando tendências e falhas do processo de institucionalização, reforço para consolidação do programa e, conseqüentemente, redução de desgastes adicionais.

\section{GRÁFICO 2}

\section{O GRAU DE INSTITUCIONALIZACAO DO SEIS SIGMA}

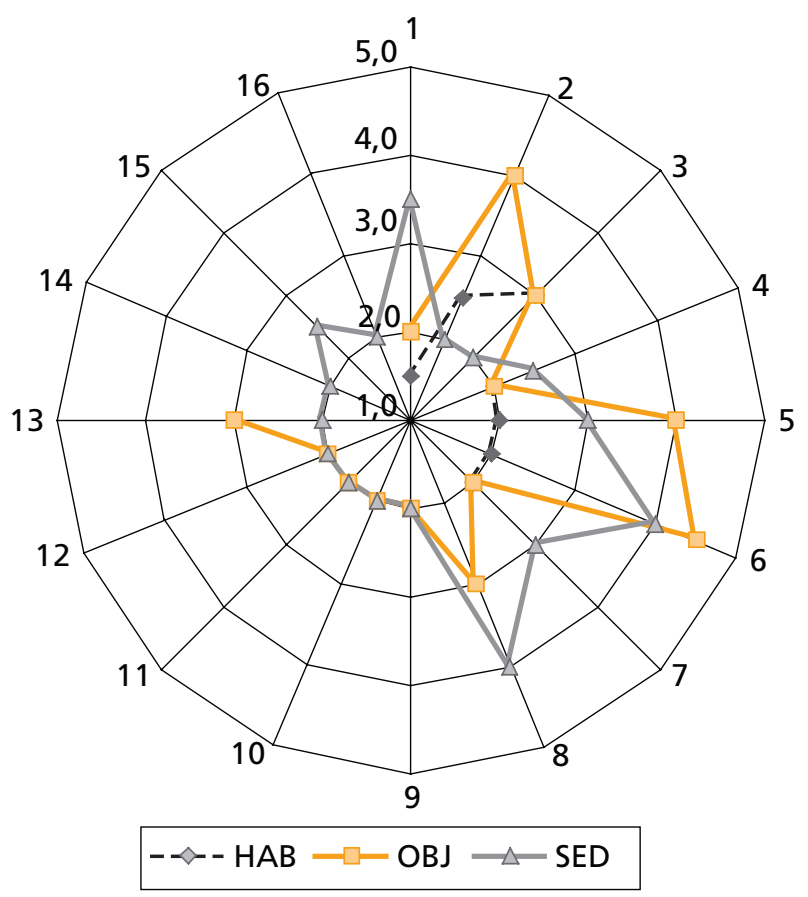

Fonte: Elaborado pelos autores.

\section{REFERỄNCIAS}

ALGARTE, W.; QUINTANILHA, D. A história da qualidade e o programa brasileiro de qualidade e produtividade. Rio de Janeiro: INMETRO/SENAI, 2000.

ANFAVEA - ASSOCIAÇÃO NACIONAL DOS FABRICANTES DE VEÍCULOS AUTOMOTORES. Relatório Anual 2004. São Paulo, 2004.

BERGER, P. L.; LUCKMANN, T. A construção social da realidade. 22. ed. São Paulo: Vozes, 2002. 
CAULCUTT, R. Why is six sigma so successful? Journal of Applied Statistics, v. 28, issue 3/4, mar. 200I.

CASTRO, N. A. Impactos sociais das mudanças tecnológicas: organização industrial e mercado de trabalho. São Paulo: Fundação Getúlio Vargas, I993.

CAMP, R. C. Benchmarking: o caminho da qualidade total. São Paulo: Pioneira, I989.

CHANNON, D. F. Benchmarking. In: COOPER, C. L.; ARGYRIS, C. (Org.). Dicionário Enciclopédico de Administração. São Paulo: Atlas, 2003.

COOPER, D. R.; SCHINDLER, P. S. Métodos de pesquisa em administração. 7. ed. Trad. Luciana de Oliveira de Rocha. Porto Alegre: Bookman, 2003.

CRUBELlATE, J. M.; GRAVE, P. S.; MENDES, A. A. A. Questão institucional e suas implicações para o pensamento estratégico. In: ENANPAD, XXVII, Atibaia, Anais... Atibaia: ANPAD, 2003.

DEFEO, J. A. The six sigma black belts: kicking quality to a new standard. The New Corporate University Review, v. 8, n. 3, 2000.

DEMING, W. E. Qualidade: a revolução da administração. I. ed. Rio de Janeiro: Marquês Saraiva, I980.

DURKHEIM, E. A sociologia de Durkheim. In: RODRIGUES, J. A. (Org.). Durkheim. 9. ed. São Paulo: Ática, 2002.

ECKES, G. A revolução seis sigma: o método que levou a GE e outras empresas a transformar pessoas em lucros. Rio de Janeiro: Campus, 200I.

ETZIONI, A. Authority structure and organization effectiveness. Administrative Science Quarterly, v. 4, issue I, p. 43-25, jun. I959.

FLECK, D. L. Active management of institutionalization process: the pathway to organizational long-term sucess. In: ENEO. Atibaia, Anais... Atibaia: ENEO, 2004.

GABOR, A. Management: Ford embraces six sigma. USA: The New York Times, jun. 200I. Disponível em:<http://www.nytimes.com/200I/06/ı3/business/ı3QUAL.html>. Acesso em: 27 maio 2004 .

GARFINKEL, H. Ethnomethodology and phenomenology. In: POWELL, W. W.; DIMAGGIO, P. J. The new institutionalism in organization analysis. Chicago: The University of Chicago Press, I99I.

HALL, P. A.; TAYLOR, R. C. R. As três versões do neo-institucionalismo. Lua Nova, n. 58, 2003.

HALL, R. H. Organizations: structures, processes, and outcomes. 7. ed. New Jersey: Prentice Hall, I999.

HASSELBLADH, H.; KALLINIKOS, J. The project of rationalization: a critique and reappraisal of neo-institutionalism in organization studies. Sweden, Greek, 2000.

H. FILHO, S. B. Os desafios da indústria automobilística. A crise da modernização. I. ed. São Paulo: IPE/USP/FIPE, I996.

HOLLANDER, E. P. Resistências a mudanças. In: COOPER, C. L.; ARGYRIS, C. (Org.). Dicionário Enciclopédico de Administração. São Paulo: Atlas, 2003. 
- O PROCESSO DE INSTITUCIONALIZAÇÃO DO SEIS SIGMA EM UMA EMPRESA AUTOMOBILÍSTICA • ROBSON QUINELLO

\section{IEDI - INSTITUTO DE ESTUDOS PARA O DESENVOLVIMENTO INDUSTRIAL.}

Carta n. 107, 2004.

JEPPERSON, R. L. Institutions, institutional effects, and institutionalism. In: POWELL, W. W.; DIMAGGIO, P. J. The new institutionalism in organization analysis. Chicago: The University of Chicago Press, I99I.

KATZ, D.; KAHN, R. L. Psicologia social das organizações. I. ed. São Paulo: Atlas, I97o. LIMA, C. L. et al. Fornecedores da Ford: uma avaliação preliminar das oportunidades de investimento na Bahia. Salvador: Estudo Setorial: Desenbahia, set. 2002.

MACHADO-DA-SILVA, C. L.; GONÇALVES, S. A. A teoria institucional. In: CLEGG, S. R.; HARDY, C.; NORDY, W. R. (Org.). Handbook de estudos organizacionais: modelos de análise e novas questões em estudos organizacionais. São Paulo: Atlas, I998.

MARCH, J. G.; SIMON, H. A. Teoria das organizações. 2. ed. Rio de Janeiro: FGV, I972. MERGULHÃO, R. C. Análise da implementação do seis sigma em empresas de manufatura no Brasil. 2003. Dissertação (Mestrado em Engenharia da Produção) - UNIFEI, Itajubá, 2003.

MEYER, J. N.; ROWAN, B. Institutionalized organizations: formal structure as myth and ceremony. In: POWELL, W. W.; DIMAGGIO, P. J. The new institutionalism in organization analysis. Chicago: The University of Chicago Press, I99I.

MITRA, A. Fundamentals of quality control and improvement. New Jersey: Prentice Hall, I998.

MORGAN, G. Imagens da organização. São Paulo: Atlas, I996.

O’BRIEN, V. MBA Compacto de negócios: soluções econômicas e idéias inovadoras. Rio de Janeiro: Campus, 2000.

POWELL, W. W.; DIMAGGIO, P. J. The new institutionalism in organization analysis. Chicago: The University of Chicago Press, I991.

PRATES, A. A. P. Organização e instituição no velho e novo institucionalismo. Departamento de Sociologia e Antropologia, FAFICH - UFMG. In: RODRIGUES, S. B.; CUNHA, M. P. Novas perspectivas na administração de empresas. São Paulo: Iglu, 2000. REVERES, Lee; BLACK, Ken. Integrating six sigma with total quality management: a case example for measuring medication errors. Journal of Healthcare Management, v. 48, p. 377-391, nov./dec. 2003.

ROBBINS, S. P. Comportamento organizacional. 8. ed. São Paulo: Prentice Hall, I998. ROMANO, B. D. Programas da qualidade na construção civil do Brasil: uma análise sob a ótica da teoria institucional. 2003. Dissertação (Mestrado em Administração) - UFES, 2003.

SCHUMPETER, J. A. A teoria do desenvolvimento econômico: uma investigação sobre lucros, capital, crédito, juro e o ciclo econômico. I. ed. São Paulo: Abril Cultural, I982. SELLTIZ, C.; WRIGHTSMAN, L.; COOK, S. Métodos de pesquisa nas relações sociais. São Paulo: USP, I975.

SELZNICK, P. A liderança na administração: uma interpretação sociológica. Rio de Janeiro: FGV, I97I. 
SMITH, D.; BLAKESLEE, J. The new strategic six sigma, v. 56, issue 9, sep. 2002. STUDT, T. Implementing six sigma in RQD, USA, v. 44, p. 2I-23, 2002.

TENNANT, Geoff . Design for six sigma launching new products and services without failure. I. ed. USA: Gower, 2002.

. Institutionalism "old" and "new". Administrative Science Quarterly. Berkeley: Conell University, I996.

TOLBERT, P. S.; ZUCKER, L. G. A institucionalização da teoria institucional. In: CLEGG, S. R.; HARDY, C.; NORDY, W. R. (Org.). Handbook de estudos organizacionais: modelos de análise e novas questões em estudos organizacionais. São Paulo: Atlas, I998.

WEBER, M. Legitimate authority and bureaucracy. In: PUGH, D. S. (Org.). Organization theory. London: Pingüim Books, 1997.

WERKEMA, C. Criando a cultura seis sigma. I. ed. Rio de Janeiro: Qualitymark, 2002.

WILLIAMSON, O. E. Comparactive economic organization: the analysis of discrete structural alternatives. Administrative Science Quarterly, v. 36, n. 2, p. 296, I99I.

- The modern corporation. In: PUGH, D. S. (Org.). Organization theory. London: Pingüim Books, I997.

YIN, R. K. Estudo de caso: planejamento e métodos. Rio de Janeiro: Bookman, 200I.

ZUCKER, L. G. The role of institutionalization in cultural persistence. In: POWELL, W.

W.; DIMAGGIO, P. J. The new institutionalism in organization analysis. Chicago: The University of Chicago Press, I991.

\section{APÊNDICE A - INSTRUMENTO DE PESQUISA (VERSÃO FINAL)}

I. Qual o número da minha "onda" (wave) de treinamento para black belt? ( ) I-3 ( ) 4-6 ( ) 7-9 ( ) IO-I2

2. Atualmente, sou um black belt: ( ) Ativo ( ) Reintegrado ou ( ) Em treinamento.

3. Qual era minha função quando ingressei no programa seis sigma na empresa atual? ( ) Horista ( ) Analista ( ) Supervisor ( ) Gerente

4. Meu departamento responde para: ( ) Manufatura ou ( ) Não-manufatura

5. Minha escolaridade no momento do ingresso do programa: () Superior incompleto () Superior completo ou ( ) Pós-graduação

6. Meu tempo "de casa" na empresa (anos): ( ) o-5 ( ) 6-Io ( ) iI-I5 ( ) mais de I6

176 7. Minha idade atual: () I8-28 ( ) 29-38 ( ) 39-48 () mais de 48

8. Qual foi minha função quando retornei do programa seis sigma na empresa atual? ( ) Horista () Analista ( ) Supervisor ( ) Gerente

Assinale com um $\mathrm{X}$ a resposta mais adequada para cada questão:

Legenda: CP (concordo plenamente), C (concordo), I (indiferente), D (discordo) e DP (discordo plenamente) 
- O PROCESSO DE INSTITUCIONALIZAÇÃO DO SEIS SIGMA EM UMA EMPRESA AUTOMOBILÍSTICA • ROBSON QUINELLO

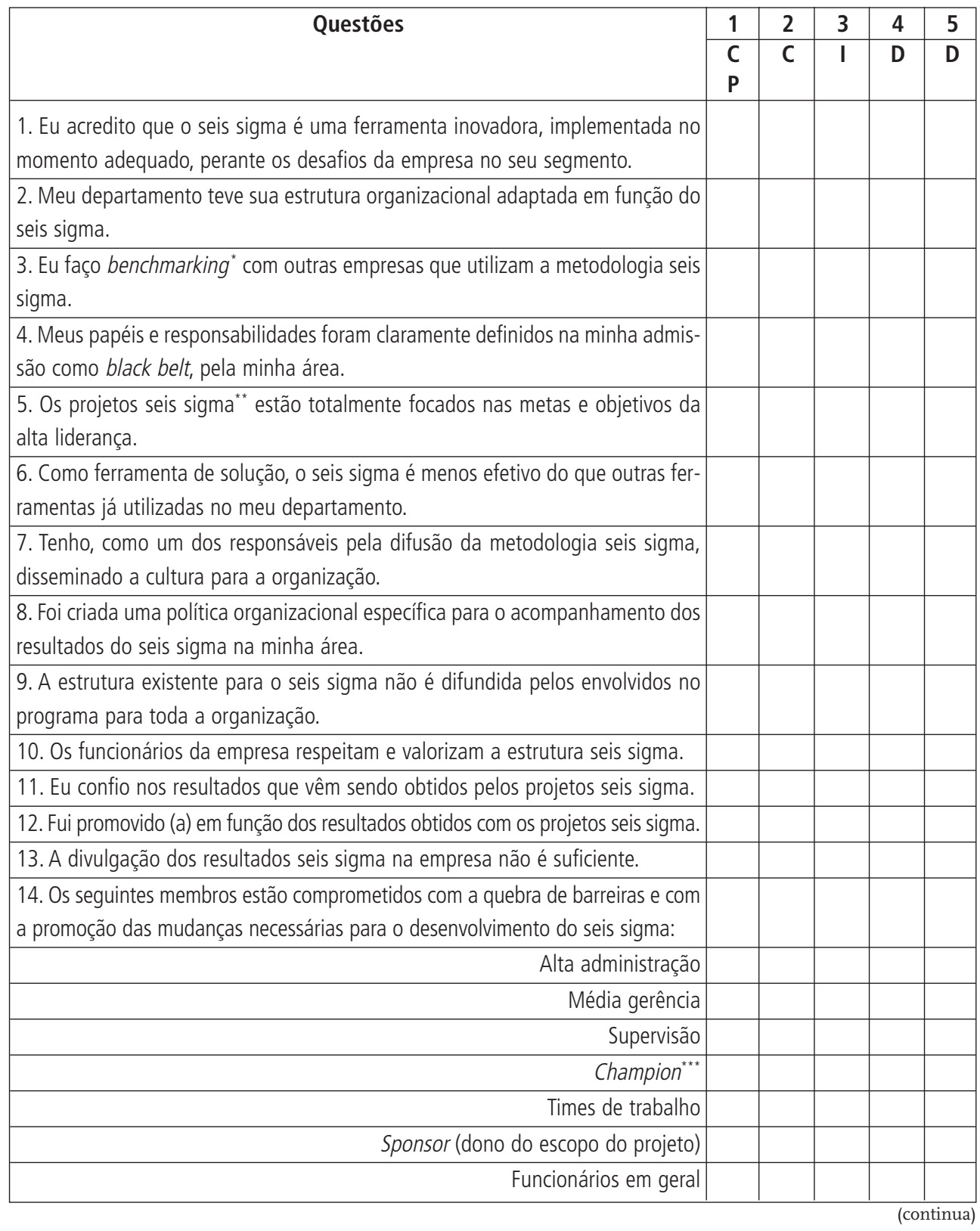

* Benchmarking é a busca pelas melhores práticas que conduzem uma empresa à maximização do desempenho empresarial (CAMP, I989).

** Projetos seis sigma são ações coordenadas pelas organizações para reduzirem variáveis que resultam em defeitos nos processos, produtos ou serviços. Esses projetos duram, em média, de quatro a seis meses.

**** Pessoa que luta por outra ou por uma causa, um defensor, um protetor (CLEGG et al., I998, p. 208). 
(continuação)

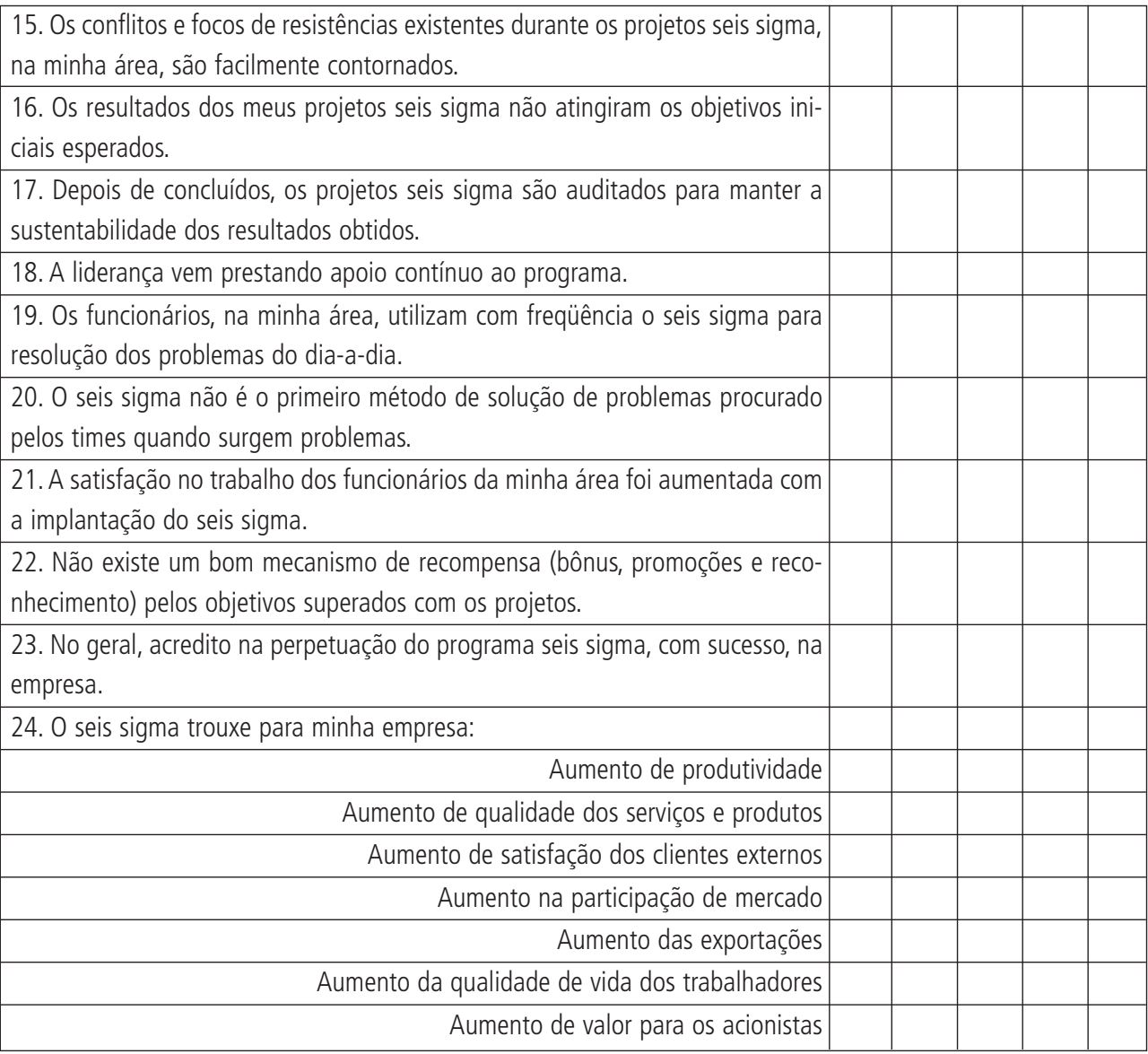

\section{TRA MITAÇÃO \\ Recebido em 24/09/2004 \\ Aprovado em 15/01/2005}


Copyright of Revista de Administração Mackenzie is the property of Universidade Presbiteriana Mackenzie, RAM-Revista de Administracao Mackenzie and its content may not be copied or emailed to multiple sites or posted to a listserv without the copyright holder's express written permission. However, users may print, download, or email articles for individual use. 